\begin{tabular}{c} 
International Journal of Engineering \& Technology, 7 (4.13) (2018) 95-98 \\
International Journal of Engineering \& Technology \\
SPC \\
Website: www.sciencepubco.com/index.php/IJET \\
Research paper \\
\hline
\end{tabular}

\title{
Development of an aircraft load planning system for distribution of passenger baggage
}

\author{
N A Jumat, E J Abdullah* \\ Department of Aerospace Engineering, Faculty of Engineering, Universiti Putra Malaysia, Malaysia \\ *Corresponding author E-mail: ermira@upm.edu.my
}

\begin{abstract}
Airplane has been widely used as transportation compared to ship or car due to the short time journey. This phenomenon contributes to high demand or airline network for many places around the world and resulted in more competition for the airline industry due to changes in economy and increase in number of airlines. Besides, the increase in price of fuel can also be a major burden to the airline to maintain or gain profit. In order to overcome the fuel and cost problem, few measures can be taken including implementing effective aircraft loading system to optimize fuel weight and manage centre of gravity (CG), an aerodynamically clean aircraft, flight planning based on good data and optimal use of systems for example bleed, flaps and gear. For this study, load planning system for a Boeing 737-800 aircraft is considered to obtain a good position of CG for better fuel consumption. A load planning system was designed and developed using LabVIEW 2016 which can easily be integrated with sensors to produce a complete system. This system capable of receiving baggage weight as input and arranging the baggage to ensure the CG location is within the stipulated range. The efficiency of this system was validated by testing an aircraft model inside a wind tunnel and observing the performance of the aircraft when loads were arrange randomly and also based on the proposed arrangement by the system. As a result from the testing, by arranging the loads using the system that has been developed, a better flight performance in term of lift to drag ratio can be obtained which was 10.2 compared to randomly arranging the loads which was 7.9. Thus, by having a good load planning can reduce the fuel consumption and also improve the flight performance.
\end{abstract}

Keywords: centre of gravity; load planning system; baggage; LabVIEW; lift to drag ratio.

\section{Introduction}

Fuel cost is the major problem for airlines. Thus it will be hard for them to maintain or gain more profit. Besides that, the manual processing method for baggage loading has been a bottleneck for airlines ground operation performances [1]. A computer based automatic load planning solution is key to improve the performance and increase efficiency. Obviously, aircraft load planning will face problem in flight, aircraft, and including the position of the baggage in the aircraft. They play the crucial role in order to make the centre of gravity (CG) lies in the limit as in the flight manual. However, there are problems when last minute changes for the aircraft to be loaded. Last minute changes in weight and balance could affect the stability of the aircraft and also safety of the passengers.

Weight and balance of an aircraft is an important topic in airline transportation [2]. The weight and balance system is divided into three common parts, which are maintaining the weight of the aircraft, maintaining the balance records and the proper loading of the aircraft. A good weight and balance system can contribute in reduced consumption of fuel [3]. The aircraft should have a configuration design based on the balance components and loads such that the CG lies in an acceptable region [4]. Besides that, the other aim to obtain a system that has the CG at the centre of its feasible interval that can allow last minute changes.
For commercial aircraft, it is crucial to have a well-managed loading system especially distribution of baggage in lower cargo. The distribution of baggage is critical because distribution of weight in each container plays a major role in aircraft balance. The luggage or baggage can be packed to the minimum number of containers before stowing the luggage or baggage [5]. The container or pallet should be filled in maximum capacity with respect to the balance of the aircraft. However, there should be a limitation in the distribution so that the CG will not exceed the limit. Then this type of configuration can help in reducing the fuel consumption and produce higher profit. The type of the compartment where the design configuration using container is shown in Figure 1 while the pallet is shown in Figure 2.

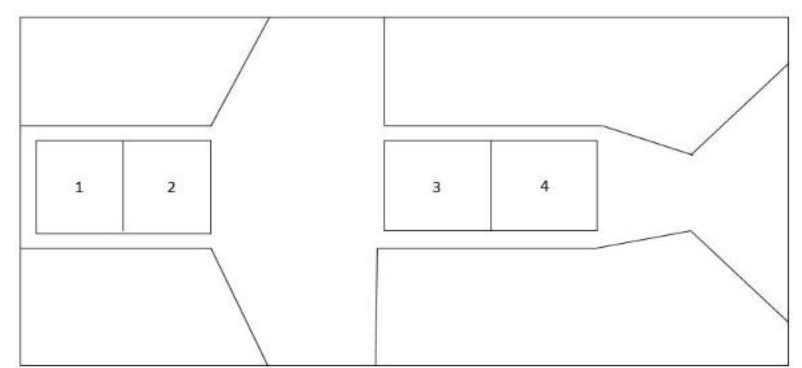

Fig. 1: Container configuration 


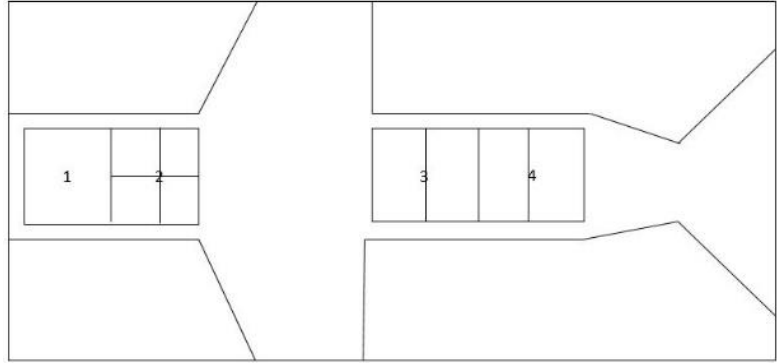

Fig. 2: Pallet configuration

When the aircraft face an overload, the condition will give a variety of problems to the aircraft such as poor manoeuvrability and controllability. Apart from that, the flight mechanism of the aircraft will be very poor where the aircraft needs a higher take-off speed and also a longer ground roll, which will contribute in high consumption of fuel [6]. Although the distribution of baggage in lower cargo is good but it has to follow the criteria of CG range. There are different limit for CG in term of \%MAC. For the forward limit during flight and forward limit for take-off and landing are $5 \%$ and $6 \%$, respectively. Meanwhile, for aft limit of CG, the aft limit is start from $22 \%$ to $26 \%$ and aft limit for flight and landing is $32.3 \%$. The load planning should consider maximum and minimum limitation of payload weight, especially the baggage in lower cargo [7].

Weights and balance is the weight of the aircraft and also the position of CG, which refers to the stability of the aircraft. Each type of aircraft has its own stability and flight envelope which the aircraft that flies within the limit CG to ensure the safety of the passengers and aircraft. Furthermore, when the aircraft has a good position of CG or between the required ranges, it can help the aircraft in terms of reduction in aerodynamics drag and fuel burnt [8]. The calculation for CG should be performed as the weight of aircraft is reduced or increased. The fuel burnt during flight is also one of the important things to be concerned with as the fuel weight will decrease and the CG should be calculated continuously. When the position of CG shifts more aft, it will also shift the curve lift coefficient $\left(C_{L}\right)$ upward as the angle attack increases [9]. When $C_{L}$ increases, lower speed is required to produce the lift and less fuel to be burnt.

In aviation industry, fuel cost is the crucial part to be considered and be paid more attention to since the fuel price rises from time to time. In order to maintain and gain profit, few solutions have been considered. There are ways to operate at minimum cost but still safe to fly the aircraft. In addition, the study shows that the gender, age and purpose of trip also contribute in the balancing of the aircraft [10]. These various factor should be analyse from time to time to generate a solution to gain optimized fuel consumption. Optimum fuel consumption can be achieved due to many aspects and one of it is when the flight planning data is accurate [11] Second, the aircraft loading is correct with respect to the take-off weight and CG of the aircraft. In addition, the aerodynamics of the aircraft is smooth and there are no disturbance from outside or inside of the aircraft. Apart from that, the speed and altitude of the aircraft have to be considered as the altitude also affect the fuel consumption [12].

At cruise level flight, $0.6 \%$ reduction in fuel consumption when the CG is $34 \%$ MAC compared to CG at $25 \%$ MAC [11]. Besides that, alternative plan should be prepared in order to maximize the profit by tracking the passenger's weight and luggage, and also the location of the respective payload. With this plan, the optimization can be employed to ensure the limit of longitudinal stability is not exceeded and still within the safe range [10]. In order to achieve the objectives of the study, a baggage system was developed. Before designing any system, a flowchart needs to be developed to make easier and manageable system. The flowchart for this study is shown in Figure 3. Then, the system can calculate the CG based on the positions and weights of the lower cargo.
The range for different lift-to-drag ratio, $L D$ was obtained based on Breguet equation as shown in Eqn. 1, where $m_{l}$ and $m_{2}$ are the initial maximum take-off weight and maximum landing weight, respectively, $R$ is the range for aircraft travel, $g$ is the gravity, $B_{f}$ is the fuel burned, $v$ is the cruise speed and $L / D$ is lift to drag ratio.

$m_{1}=m_{2} \cdot e^{\left(\frac{R \cdot g \cdot B}{v \cdot \frac{L}{D}}\right)}$

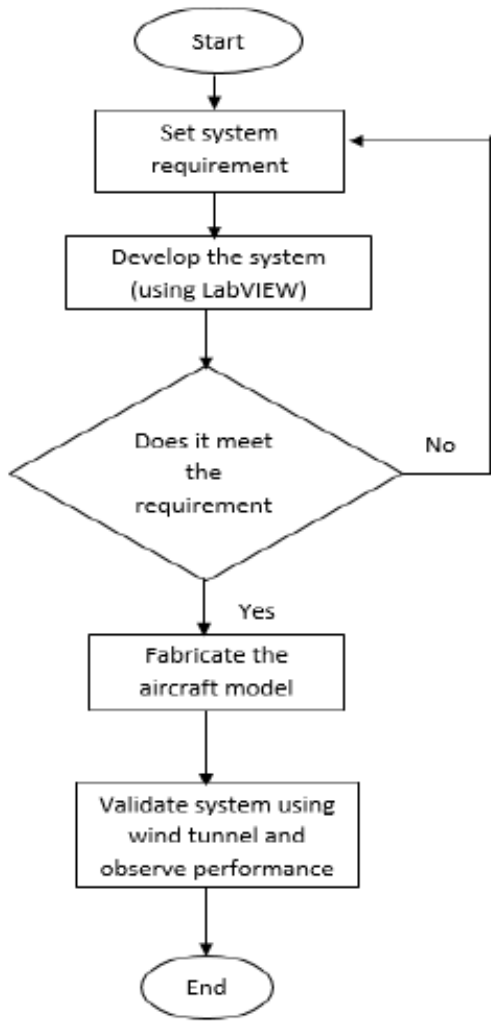

Fig. 3: Flow of the project

\section{Load planning system development}

Basically, a system was designed and developed using LabVIEW 2016 (Full Development System) after choosing one type of aircraft, the Boeing 737-800, a commercial aircraft. An algorithm or flowchart for the system was designed as a reference to develop the system. Each block had different value of baggage weight that was allowed to be loaded in the container or pallet. After the system was complete, validation of the system was done through testing an aircraft model inside an open loop wind tunnel. The results obtained were analysed to compute the lift to drag ratio. The performance of the aircraft has a direct correlation to the fuel consumption of the aircraft during cruise flight.

For this study, LabVIEW was used as it can be easily interfaced with the hardware to provide an integrated solution. LabVIEW was used due to ease of assembly for all the components such as data acquisition, test and control system. This method to ensure that the optimization does not violate the safety of the aircraft. This system could help to solve any contingency problem within few minutes. The design of arrangement loads as in Figure 3 based on specification of 737-800 as shown in Table 1.

The system was designed to arrange the baggage by flow, where every time customers check in any baggage, the baggage will be distributed starting from block 1 until block 4 and the process was repeated so that there will no empty block when the aircraft flies as in Figure 4 and Figure 5. Each block has a range of weight of baggage to be inserted so that it will not exceed the limit of applicable weight. The first input inserted weight which is below than 
$50 \mathrm{~kg}$ goes to the respective block. After inserting all the desired weight then the total weight inserted in the second input of weight then the CG baggage automatically calculated.

Table 1: Specifications of 737-800

\begin{tabular}{|c|c|}
\hline Passengers & $\begin{array}{c}\text { Typical 1-class configuration : } 189 \\
\text { Typical 2-class configuration : } 160\end{array}$ \\
\hline Propulsion & 2 (Turbofan Engines) \\
\hline Engine model & CFM Intl. CFM56-7B27 \\
\hline Engine power (each) & $121.4 \mathrm{kN}$ \\
\hline Speed & $946 \mathrm{~km} / \mathrm{h}$ \\
\hline Max. Mach & 0.82 \\
\hline Service ceiling & $12497 \mathrm{~m}(41000 \mathrm{ft})$ \\
\hline Range & $7408 \mathrm{~km}$ \\
\hline Empty Weight & $41413 \mathrm{~kg}$ \\
\hline Max. take-off weight & $78245 \mathrm{~kg}$ \\
\hline Max. landing weight & $65317 \mathrm{~kg}$ \\
\hline Wing span & $34.32 \mathrm{~m}$ \\
\hline Wing area & $124.6 \mathrm{~m}$ \\
\hline Length & $39.5 \mathrm{~m}$ \\
\hline Height & $12.57 \mathrm{~m}$ \\
\hline
\end{tabular}

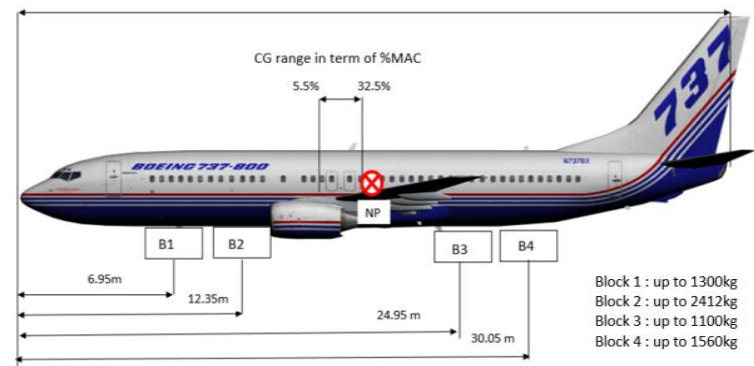

Fig. 4: Weight and position for block

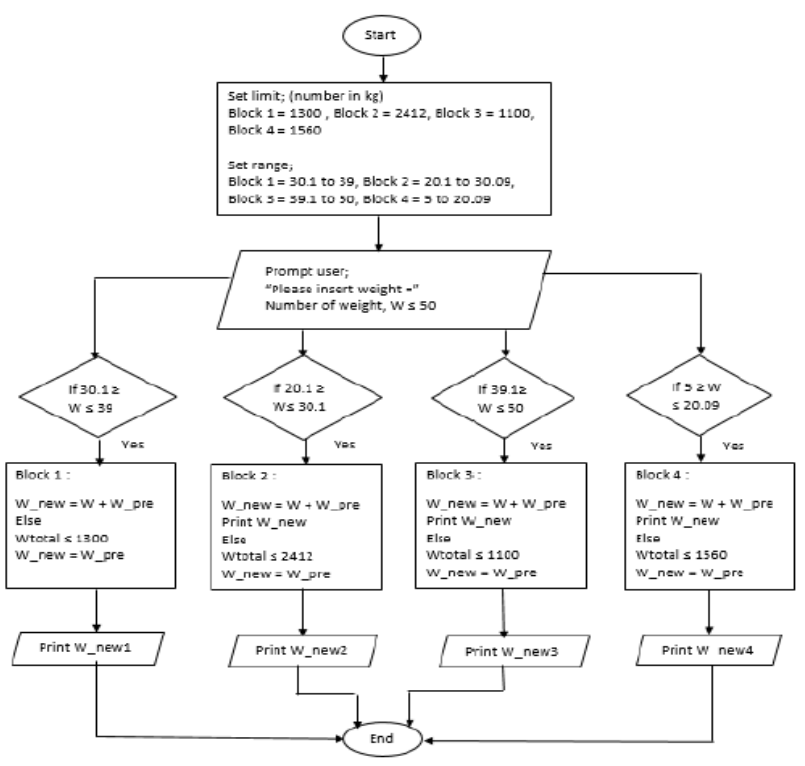

Fig. 5: Flow for baggage arrangement

\section{Proof of concept}

First of all, the system was tested. The baggage was desired to be placed according to the weight range for each block. The desired arrangements are as follows;

a. BLOCK $1(6.95 \mathrm{~m})$ :- range: $5.0 \mathrm{~kg}$ until $20.09 \mathrm{~kg}$, limit: up to $1560 \mathrm{~kg}$ b. BLOCK $2(12.35 \mathrm{~m})$ :- range: $30.1 \mathrm{~kg}$ until $39 \mathrm{~kg}$, limit: up to $1300 \mathrm{~kg}$ c. BLOCK $3(24.95 \mathrm{~m})$ :- range: $20.1 \mathrm{~kg}$ until $30.09 \mathrm{~kg}$, limit: up to $2412 \mathrm{~kg}$ d. BLOCK 4 (30.05 m):- range: $39.1 \mathrm{~kg}$ until $50 \mathrm{~kg}$, limit: up to $1100 \mathrm{~kg}$

The range are the weight of the passenger's baggage. The system will allocate the baggage according the desired sequence. The system was validated using wind tunnel testing. An aircraft model was tested inside a wind tunnel and the results obtained to observe the lift to drag ratio. The dimensions of the aircraft model as in
Figure 6 and as in Figure 7, the schematic inside the green square is the test area. The aircraft model mounted on the rods which were divided into three rods. Two rods were mounted in the middle part of the aircraft model to hold the aircraft model in place during the experiment while the tail part mounted for pitch. The pitch angle can be changed by adjusting the height of the rod. For close up in Figure 7, Rod A consisted of two rods which held the aircraft model body to prevent any movement during testing. Rod $\mathrm{B}$ for pitching but for this experiment, pitch angle was $0^{\circ}$ since desired flight was cruise and level flight.

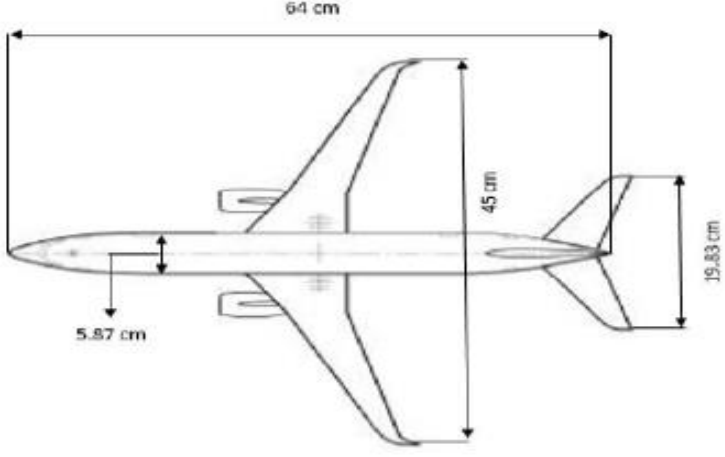

Fig. 6: Dimensions of aircraft model (top view)

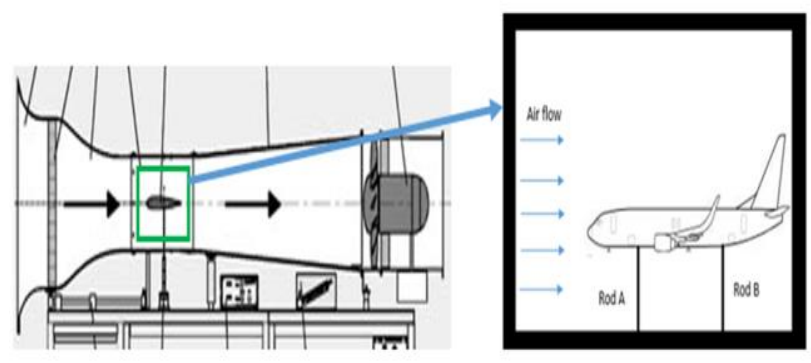

Fig. 7: Schematic diagram for open loop low speed wind tunnel

By scaling the weight, $(2.1 \mathrm{~kg} / 6372 \mathrm{~kg}=0.00033)$ where $2.1 \mathrm{~kg}$ is the total weight used in the aircraft model while $6372 \mathrm{~kg}$ is the actual weight for the four blocks. The weights were arranged in two different arrangements, first for the arrangement based on system $(25.42 \% \mathrm{MAC})$, where 1 st block $=0.4 \mathrm{~kg}, 2 \mathrm{nd}$ block $=$ $0.5 \mathrm{~kg}, 3 \mathrm{rd}$ block $=0.8 \mathrm{~kg}$ and $4 \mathrm{th}$ block $=0.4 \mathrm{~kg}$ while for the second arrangement for randomly arrange the block $(16.13 \%)$, where $1 \mathrm{st}$ block $=0.4 \mathrm{~kg}, 2$ nd block $=0.5 \mathrm{~kg}, 3 \mathrm{rd}$ block $=0.4 \mathrm{~kg}$ and $4 \mathrm{th}$ block $=0.8 \mathrm{~kg}$. Figure 8 shows the example of arrangement of the weights.

Based on the calculation by using Breguet equation, the difference of $\mathrm{R}$ between baggage arrange based on system and randomly arrange the baggage is $21.79 \%$. This show that the system can improve the fuel efficiency by consider the L/D. A good position of CG will help to obtain the desired L/D.

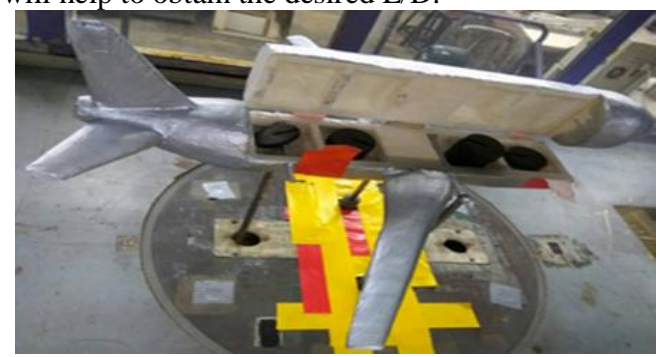

Fig. 8: Weights inside the aircraft model

\section{Result and discussion}

The CG for maximum total weight of baggage is $25.42 \% \mathrm{MAC}$ as in Figure 9 while for the minimum total weight is $27.71 \%$ MAC as 
in Figure 10. Both CG are within the range and it shows that the system is applicable to be used.

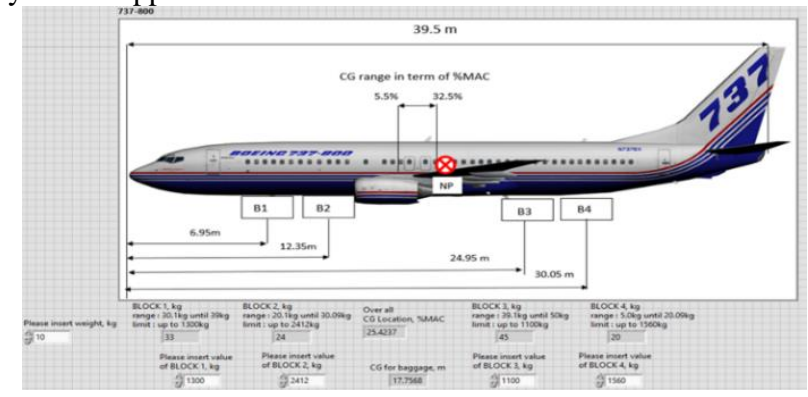

Fig. 9: User interface system for maximum total weight

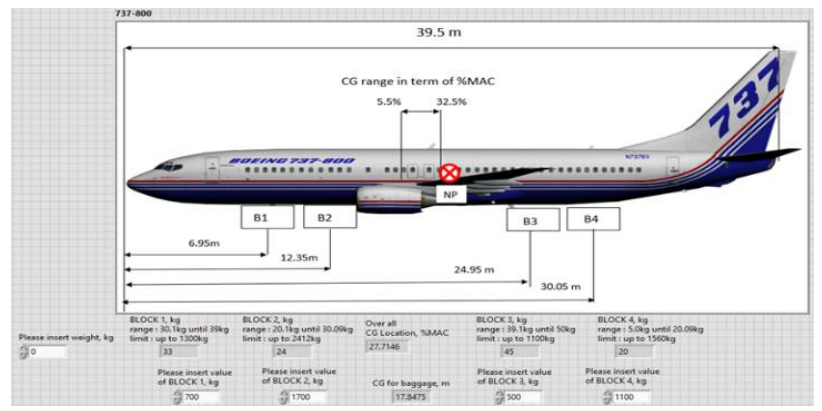

Fig. 10: User interface system for minimum total weight

In addition, when the weights were arranged randomly, the CG obtained was $16.13 \%$ MAC which was forward CG. Forward CG resulted in higher stall speed where the aircraft flies at higher angle of attack to increase the lift. This situation lead to high induced drag that produced by the wings and consume more fuel compare to aft CG (25.42\% MAC). At aft CG, the aircraft flies at lower angle of attack and requires lower down force at the tail to produce lift which means decrease in induced drag resulting in low consumption of fuel.

Based on Figure 11, the $L / D$ curve shows that the maximum $L / D$ for first weight arrangement was higher at 10.2 compared to second weight arrangement which was 7.9. From the observation, the randomly arranged weights have forward $\mathrm{CG}$ and proper arranged weights have aft CG, $16.13 \%$ MAC and $25.42 \%$ MAC, respectively and the aircraft model was tested at 0 degree of pitch angle which was cruise and level flight. The reason randomly arranged of weights have low lift to drag ratio due to 0 degree of pitch angle and lift produce was very low compare to aft CG, low pitch angle can produce high lift due to low induced drag and down force tail. When this situation was applied to the real aircraft, forward CG consumes more fuel compared to aft $\mathrm{CG}$ due to induced drag produced by forward CG is higher than induced drag produce by aft CG. High induced drag requires high amount of thrust to counteract the problem, which increases fuel consumption and hence it is an inefficient way to maintain level flight.

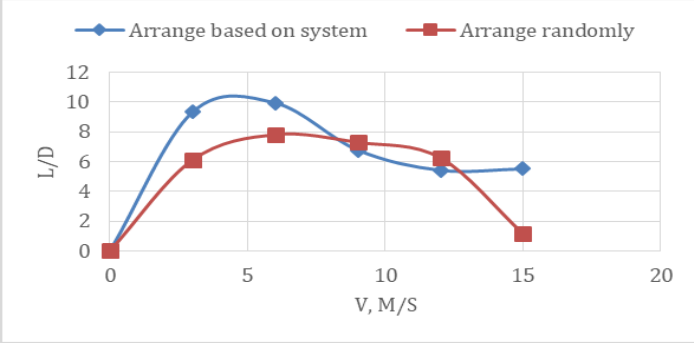

Fig. 11: $L D$ curve against speed of wind tunnel

\section{Conclusion}

In this study, an aircraft load planning system has been successfully developed and tested. A good planning in weight arrangement can improve the performance in term $L / D$, thus help reduce the fuel consumption. This load planning system was designed by arranging the loads at lower cargo at proper arrangement and in order to obtain the desired CG which is the aft CG to help in reducing fuel consumption. From the system, the maximum weight loaded into the aircraft gives aft CG which is $25.42 \%$ MAC compared to forward CG which is $16.13 \%$ MAC. In order to validate the system, a wind tunnel testing has been conducted and the results show that the proper arrangement of weight gives higher lift to drag ratio compared to randomly arranged weights. Although there are many methods to reduce fuel consumption, but by having a good planning system results in lower amount of fuel consumption apart from ensuring the stability of the aircraft. It is important to ensure that the weight and balance are within the limits and the loads are secured properly. Besides, an extra consideration for loading can improve flight performance and efficiency.

\section{Acknowledgement}

The authors would like to acknowledge that the research findings presented in this paper is funded by the Research University Grant Scheme (RUGS): UPM/700-2/1/GPB/2017/9530800 from Universiti Putra Malaysia.

\section{References}

[1] Verstichel J, Vabcroonenburg W, Souffriau W \& Berghe GV (2011), A mixed integer programming approach to the aircraft weight and balance problem. Procedia - Social and Behavioral Sciences 20, 1051-1059

[2] Fok K, Ka M, Chun A \& Wai H (2004), Optimizing air cargo load planning and analysis. International Conference on Computing, Communication and Control Technologies

[3] Gabriel T, José M, Gamboa P, Silva J, Viegas J \& Leal N (2009), An optimized approach to reduced fuel costs in the operational procedures of an airline. World Congress on Structural and Multidisciplinary Optimization

[4] van Es GWH (2007), Analysis of aircraft weight and balance related safety occurrence, European Aviation Safety Seminar

[5] Vancroonenburg W, Verstichel J, Tavernier K \& Berghe GV (2014), Automatic air cargo selection and weight balancing: a mixed integer programming approach. Logistic and Transportation Review 65, 70-75

[6] Stefani R (2005), Aircraft weight and balance system. Patent No. $6,923,375$ B2

[7] Limbourg S, Schyns M \& Laporte G (2012), Automatic aircraft cargo load planning system. The Journal of the Operational Research Society 63(9), 1271-1283

[8] The Sabre Airline Solutions (2008), A discussion of fuel cost containment relevant to load planning. White Paper

[9] Gabriel T, Silva JM, Gamboa P, Silva J, Viegas J \& Leal N (2009), An optimized approach to reduced fuel costs in the operational procedures of an airline. World Congress on Structural and Multidisciplinary Optimization

[10] Berdowski Z, van den Broek-Serie FN, Jetten JT, Kawabata Y, Schoemaker JT \& Versteegh R (2009), Survey on standard weights of passengers and baggage. European Aviation Safety Agency

[11] ATR Customer Service (2011), Fuel saving: contributing to a sustainable air transport development. ATR

[12] Horan S (2016), Using Labview to design a payload control system. International Telemetering Conference 